\title{
Physiological Studies in Buffaloes Affected with Diaphragmatic Hernia with Different Treatment Protocols
}

\author{
Lokesh $^{1}$, Praveen Kumar ${ }^{1 *}$, Anup Yadav ${ }^{1}$, Ashwani kumar ${ }^{1}$, Rishi Tayal ${ }^{2}$, \\ PankajKumar ${ }^{3}$, RajendraYadav ${ }^{4}$ and R.P. Diwakar ${ }^{5}$ \\ ${ }^{1}$ Department of Animal Husbandry, Govt. of Haryana, India \\ ${ }^{2}$ Veterinary Surgery and Radiology, (LUVAS, Hisar), India \\ ${ }^{3}$ ADIO, Disease Investigation Lab., Rohtak (LUVAS, Hisar), India \\ ${ }^{4}$ Animal Health Specialist (Vety. Medicine), RVDEC, \\ Mahendergarh (LUVAS, Hisar), India \\ ${ }^{5}$ Department of Veterinary Microbiology, C.V.Sc\&A.H., N.D.U.A\&T., Kumarganj, Faizabad \\ (U.P), India
}

*Corresponding author

\section{A B S T R A C T}

\section{Keywords \\ diaphragmatic hernia, buffaloes, rectal temperature, heart rate and respiratory rate \\ Article Info \\ Accepted: \\ 10 November 2018 \\ Available Online: \\ 10 December 2018}

The study was conducted in eighteen buffaloes categorised into three groups of six animals each. The drugs were used in following combinations: Glycopyrrolate-XylazineMeloxicam-Ketamine, Glycopyrrolate-Xylazine-Tolfenamic acid-Ketamine and Glycopyrrolate-Xylazine-Flunixin-meglumine-Ketamine. Glycopyrrolate was given @ $0.01 \mathrm{mg} / \mathrm{kg}$ body weight i/m, Xylazine @ $0.04 \mathrm{mg} / \mathrm{kg}$ body weight i/m, Meloxicam at 0.5 $\mathrm{mg} / \mathrm{kg}$ body weight i/m, Tolfenamic acid $4 \mathrm{mg} / \mathrm{kg}$ body weight i/m, Flunixin-meglumine at $2.2 \mathrm{mg} / \mathrm{kg}$ body weight i/v and Xylazine and Ketamine @ $0.04 \mathrm{mg} / \mathrm{kg}$ body weight i/v and $1 \mathrm{mg} / \mathrm{kg}$ body weight $\mathrm{i} / \mathrm{v}$ for induction and maintenance were given. In all the groups, rectal temperature, heart rate and respiratory rate fluctuated non-significantly during entire period of observations.

\section{Introduction}

Diaphragmatic hernia is defined as the passage of abdominal viscera into the thoracic cavity through a congenital or acquired opening in the diaphragm at the musculotendinous junction. It is a chronic wasting and inflammatory thoracoabdominal disorder in adult milk buffaloes (Sahu et al., 2003) and has also been reported in cows (Saini et al., 2007) and buffalo bulls (Sobti et al., 1989). The various symptoms range from chronic ruminal tympany, anorexia to displacement of the heart (Radostits et al., 2007). Its high prevalence reported in buffaloes especially from North India. The possible aetiological factors include weakening of diaphragm by lesions of traumatic reticuloperitonitis, 
congenital weak points of diaphragm and physical force like increased intra-abdominal pressure during pregnancy or act of parturation. The disease is generally associated with the presence of foreign bodies in the reticulum. The situation of diaphragmatic hernia is serious, as if it remains untreated causes death in $100 \%$ cases (Krishnamurthy et al., 1985).

Treatment of diaphragmatic hernia requires surgery in two stages. The first stage involves a laparo-rumenotomy that enables the surgeon to assess the location and extent of herniation, retract and remove foreign bodies. During the second stage of surgery, the repair of the diaphraghmatic defect is done under general anaesthesia along with controlled ventilation (Singh et al., 2006). There is severe pain during the time of diaphragmatic herniorrhaphy. To achieve anaesthesia and relieve the pain different analgesic drugs are used which act on peripheral and central nervous system.

General anaesthesia is a state of reversible unconsciousness produced by a process of controlled, reversible drug-induced intoxication of the central nervous system in which the patient neither perceives nor recalls noxious stimuli (Hall et al., 2001). General anaesthesia in bovines causes various complications like excessive salivation, regurgitation, tympany and cardiopulmonary depression. So a multiple drug approach (balanced anaesthesia and analgesia) is exploited to minimize and attenuate sensory, motor, sympathetic and parasympathetic reflex activities. Due to this reason, it becomes imperative to evaluate each sedative or preanaesthetic drug before clinical use.

Glycopyrrolate has a powerful and prolonged antisialogogue activity and is about five times as potent as Atropine (Hall et al., 2001a). It is a preanaesthetic drug which stimulates cardiac reflex and blocks vagus reflex, thus prevents or inhibits cardiac inhibitory effect of Xylazine. Xylazine administration produces profuse salivation in cattle as recorded by Kumar and Singh (1979). It produced tachycardia (Khan et al., 2007a) in buffalo calves and that it when administered after Xylazine administration caused increased heart rate and mean arterial pressure (Khan et al., 2007b). Disadvantage of Glycopyrrolate to produce tachycardia and also associated to increase in oxygen demand which may result in arrhythmias or reduced cardiac contractility (Hall and Clarke, 1991).

Xylazine is typical $\alpha_{2}$-adrenoceptor agonist and exerts its effect accordingly. There is marked variation in susceptibility to Xylazine's effect in various species of domestic animals. In cattle administration of Xylazine $(0.5 \mathrm{mg} / \mathrm{kg}$, IM) produced deep sedation with animal going into lateral recumbency (Hall and Clarke, 1969).

Ketamine is a dissociative anaesthetic that is used for induction/maintenance of anaesthesia in many species. It has the tendency to cause catalepsy and occasional seizers (Pageat, 1986). Pathak et al., (1982) reported the drawback of muscular rigidity with Ketamine. These demerits potentiate the necessity for the use of preanaesthetics having muscle relaxation properties along with or prior to induction and or maintenance of anaesthesia with Ketamine.

Although a common concern for the welfare of the animals is shared, the prevention and alleviation of pain has not always been implemented effectively. Misconceptions about the nature and significance of pain, difficulties in recognizing its severity and uncertainly as to the most appropriate therapy have all hampered progress in this area, particularly in bovines. 
Post-operative pain is commonly managed by Nonsteroidal anti-inflammatory drugs (NSAIDs)/ opioid (Dar et al., 2013). NSAIDs are used extensively in veterinary practice for their analgesic, anti-inflammatory and antipyretic effects. Nonsteroidal antiinflammatory drugs (NSAIDs) have been reported to be extremely effective postoperative analgesics (Mathews, 2001).

Flunixin-meglumine is a carboxylic acid nonsteroidal anti-inflammatory drug and a potent inhibitor of cyclooxygenase (Semrad $e t$ al., 1985). In horses, Flunixin-meglumine is indicated for alleviation of inflammation and pain associated with musculoskeletal disorders and visceral pain associated with pain.

Tolfenamic acid belongs to the fenamate group and is a potent inhibitor of cyclooxygenase enzyme. It is efficient in treatment of chronic and acute painful locomoter syndromes in the dog (Lecoindre et al., 1995).

Meloxicam is an oxicam (enolic acid) derivative. Meloxicam has preferential COX-2 activity and is also a mild inhibitor of COX-1 in platelets and kidneys (Deneuche et al., 2004). It is indicated for the management of inflammation and pain arising from acute and chronic diseases (Lascelles et al., 2001).

Meloxicam, Tolfenamic acid and Flunixinmeglumine have not been tried earlier as preemptive analgesia in combination with Glycopyrrolate - Xylazine - Ketamine anaesthesia in buffaloes undergoing diaphragmatic harniorrhaphy (D.H.). Therefore, the present study was undertaken to evaluate the physiological changes in buffaloes treated with under given drugs schedule.

Group 1 Glycopyrrolate - Xylazine Meloxicam - Ketamine in buffaloes undergoing diaphragmatic herniorrhaphy.
Group 2 Glycopyrrolate - Xylazine Tolfenamic acid - Ketamine in buffaloes undergoing diaphragmatic herniorrhaphy.

Group 3 Glycopyrrolate -Xylazine - Flunixinmeglumine - Ketamine in buffalo undergoing diaphragmatic herniorrhaphy.

\section{Materials and Methods}

The present investigation was conducted on eighteen clinical cases of buffaloes suffering from diaphramatic hernia presented to the Teaching Veterinary Clinical Complex, LUVAS, Hisar from August 2013 to May 2014.

Diaphragmatic hernia was confirmed by radiography and rumenotomy. In positive cases, the ruminal contents were evacuated completely by laparo-rumenotomy and thereafter diaphragmatic hernia repair was done under general anaesthesia. Each animal was weighed before the diaphragmatic herniorraphy for calculating the proper dose of drugs used for general anaesthesia and kept off feed and water after laparo-rumenotomy and these animals were kept strictly on fluid therapy to avoid regurgitation during operation.

The animals were divided into three groups of six animals each. Pilot trials were done to standardize the dose rates and route of administration of different drugs.

Rectal temperature, heart rate (by auscultation) and respiration rate were recorded just before administration of the $\operatorname{drug}(\mathrm{s})$ along with the ambient temperature to form the base values. The blood samples were collected from jugular venipuncture before rumenotomyi.e before administration of the drugs, before diaphragmatic herniorraphy, 15 minutes after administration of Meloxicam/ Tolfenamic acid/Flunixin-meglumine, 5 
minutes after administration of Ketamine, after complete recovery from the effects of the drugs and at 24 hour after recovery.

Various physiological parameters were recorded at before rumenotomy, before diaphragmatic herniorrhaphy, 15 minutes after Glycopyrrolate, 10 minutes after Xylazine, and 15 minutes after Meloxicam/Tolfenamic acid/Flunixin-meglumine administration at recovery and 24 hours after diaphragmatic herniorrhaphy.

Drugs given in Table 1 are used in different combinations for repair of diaphragmatic hernia.

\section{Statistical analysis}

The statistical analysis of data was done by one-way-analysis of variance and Duncan's multiple range test (Duncan, 1955).

\section{Results and Discussion}

\section{Group 1: Glycopyrrolate-Xylazine- Meloxicam-ketamine}

\section{Physiological study}

The effect of Glycopyrrolate-XylazineMeloxicam-Ketamine combination on rectal temperature, heart rate and respiratory rate are shown in table 2 and Figure 1. A nonsignificant increase in heart rate was observed just before the animal was operated for diaphragmatic herniorrhaphy from the base value $45.59 \pm 9.20$ to $54.16 \pm 1.72$ beats per minute, then it maintained that level throughout the period of observation with nonsignificant variation. There was apnoea after three to five minutes of Ketamine administration in all the animals, endotracheal tube was passed into the trachea after relaxation of laryngeal muscles for maintenance of intermittent positive pressure ventillation at the rate of twelve breaths per minute. Respiration rate and rectal temperature showed non-significant variation during the entire period of observation.

\section{Group 2: Glycopyrrolate-Xylazine- Tolfenamic acid-- Ketamine}

\section{Physiological study}

The effect of Glycopyrrolate-XylazineTolfenamic acid-Ketamine combination on rectal temperature, heart rate and respiratory rate are shown in table 3 and Figure 2. There was no significant variation in rectal temperature during the entire period of observation. The values of respiratory rate and heart rate fluctuated non-significantly at various intervals.

\section{Group 3: Glycopyrrolate-Xylazine- Flunixin-Meglumine-Ketamine}

\section{Physiological Study}

The effect of Glycopyrrolate-XylazineFlunixin-meglumine-Ketamine combination on rectal temperature, heart rate and respiratory rate are shown in table 4 and Figure 3. There was no significant variation in rectal temperature during the entire period of observation. The values of respiratory rate and heart rate fluctuated non-significantly at various intervals.

\section{Group 1}

\section{Physiological study}

No significant variations were observed in rectal temperature, heart and respiratory rates during the entire period of observation. No effect on heart rate was observed by Sharma et al., (1983) in cattle given Xylazine $(0.1 \mathrm{mg} / \mathrm{kg})-$ Ketamine anaesthesia either by intramuscular $(5 \mathrm{mg} / \mathrm{kg})$ or intravenous route $(2 \mathrm{mg} / \mathrm{kg})$. 
Table.1 Following drugs were used in different combinations for repair of diaphragmatic hernia

\begin{tabular}{|c|c|c|}
\hline Drugs & $\begin{array}{c}\text { Dose rate } \\
(\mathrm{mg} / \mathrm{kg})\end{array}$ & $\begin{array}{c}\text { Time and route of administration } \\
\text { of different drugs }\end{array}$ \\
\hline Glycopyrrolate $^{1}$ & 0.01 & \multirow{6}{*}{$\begin{array}{l}\text { Glycopyrrolate(I/M) } \\
\text { Xylazine(I/M) } \\
\text { Meloxicam (I/M)/ Tolfenamic acid (I/M)/ } \\
\text { Flunixin-meglumine (I/V) } \\
15 \text { minutes } \\
\text { Ketamine + Xylazine (I/V) }\end{array}$} \\
\hline Xylazine $^{2}$ & 0.04 & \\
\hline Meloxicam $^{3}$ & 0.5 & \\
\hline Tolfenamic acid ${ }^{4}$ & 4 & \\
\hline Flunixin-meglumine $^{5}$ & 2.2 & \\
\hline Ketamine $^{6}+$ Xylazine & $1+0.04$ & \\
\hline
\end{tabular}

${ }^{1}$ PyrolateR- Glycopyrrolate injection U.S.P. $(0.2 \mathrm{mg} / \mathrm{ml})$, Neon Laboratories Limited, 28, Mahal Ind. Estate, M. Caves Road, Andheri [East], Mumbai - 400093, INDIA.

${ }^{2}$ Xylazine - Xylazine injection $(23.32 \mathrm{mg} / \mathrm{ml})$, Indian Immunologicals Ltd., Gollapadu, Guntur Dist- 522408 A.P.

${ }^{3}$ Aneket - Ketamine Hydrochloride Injection I.P. $50 \mathrm{mg} / \mathrm{ml}$, Neon Laboratories Limited, 28, Mahal Ind. Estate, M. Caves Road, Andheri [East], Mumbai - 400093, INDIA.

${ }^{4}$ FlunimegTM -Flunixin-meglumine Injection I.P. $50 \mathrm{mg} / \mathrm{ml}$, ZydusAHL, Astron Tech Park, satellite cross roads Ahmedabad-380015, INDIA..

${ }^{5}$ ZobidTM_M Vet-Meloxicam injection(vet) I.P. 5mg/ml, Zydus AHL, Astron Tech Park, satellite cross roads Ahmedabad-380015, INDIA..

${ }^{6}$ MaxxtolTM -Tolfenamic injection I.P. 40mg/ml, Intas Pharmaceuticals Ltd. Matoda-382210 Ahmedabad, INDIA

Table.2 Effects of Glycopyrrolate-Xylazine-Meloxicam-Ketamine combination on rectal temperature, heart rate and respiratory rate in six buffaloes. Mean values

presented with respective standard errors $( \pm)$

\begin{tabular}{|c|c|c|c|c|c|c|c|}
\hline Parameters (Units) & $\mathrm{T} 1$ & $\mathrm{~T} 2$ & T3 & $\mathrm{T} 4$ & T5 & T6 & $\mathrm{T} 7$ \\
\hline $\begin{array}{l}\text { Ambient } \\
\text { temperature }\left({ }^{\circ} \mathrm{C}\right)\end{array}$ & $26.08 \pm 1.01^{\mathrm{a}}$ & $26.58 \pm 1.21^{\mathrm{a}}$ & $26.58 \pm 1.21^{\mathrm{a}}$ & $26.58 \pm 1.21^{\mathrm{a}}$ & $26.58 \pm 1.21^{\mathrm{a}}$ & $26.58 \pm 1.21^{\mathrm{a}}$ & $26.41 \pm 1.24^{a}$ \\
\hline $\begin{array}{l}\text { Rectal temperature } \\
\left({ }^{\circ} \mathrm{C}\right)\end{array}$ & $37.79 \pm 0.14^{\mathrm{a}}$ & $37.88 \pm 0.12^{\mathrm{a}}$ & $37.90 \pm 0.10^{\mathrm{a}}$ & $37.98 \pm 0.11^{\mathrm{a}}$ & $37.83 \pm 0.17^{\mathrm{a}}$ & $37.75 \pm 0.23^{\mathrm{a}}$ & $37.86 \pm 0.16^{a}$ \\
\hline $\begin{array}{l}\text { Respiratory rate } \\
\text { (Breaths per } \\
\text { minutes) }\end{array}$ & $17.66 \pm 0.91^{\mathrm{a}}$ & $18.33 \pm 0.95^{\mathrm{a}}$ & $17.16 \pm 0.83^{\mathrm{a}}$ & $15.66 \pm 0.95^{\mathrm{a}}$ & $22.16 \pm 7.21^{\mathrm{a}}$ & $14.00 \pm 0.73^{\mathrm{a}}$ & $15.66 \pm 1.11^{\mathrm{a}}$ \\
\hline $\begin{array}{l}\text { Heart rate (beats } \\
\text { per minute) }\end{array}$ & $45.50 \pm 9.20^{\mathrm{a}}$ & $54.16 \pm 1.72^{a}$ & $56.33 \pm 1.74^{a}$ & $54.16 \pm 1.47^{\mathrm{a}}$ & $53.16 \pm 1.55^{\mathrm{a}}$ & $52.50 \pm 2.50^{\mathrm{a}}$ & $55.83 \pm 1.86^{\mathrm{a}}$ \\
\hline
\end{tabular}

Means with same superscripts do not vary significantly ( $\mathrm{p}>0.05)$

T1: Before Rumenotomy, T2: Before Diaphragmatic herniorrhaphy, T3: 15 minutes after Glycopyrrolate, T4: 10 minutes after Xylazine, T5: 15 minutes after Meloxicam, T6: At recovery, T7: 24 hours after Diaphragmatic herniorrhaphy 
Table.3 Effects of Glycopyrrolate-Xylazine-Tolfenamic acid-Ketamine combination on rectal temperature, heart rate and respiratory rate in six buffaloes. Mean value presented with respective standard errors $( \pm)$

\begin{tabular}{|c|c|c|c|c|c|c|c|}
\hline $\begin{array}{l}\text { Parameters } \\
\text { (Units) }\end{array}$ & $\mathrm{T} 1$ & $\mathrm{~T} 2$ & $\mathrm{~T} 3$ & $\mathrm{~T} 4$ & T5 & T6 & $\mathrm{T} 7$ \\
\hline $\begin{array}{c}\text { Ambient } \\
\text { temperature }\left({ }^{\circ} \mathrm{C}\right)\end{array}$ & $5.91 \pm 1.06^{\mathrm{a}}$ & $6.58 \pm 1.16^{\mathrm{a}}$ & $6.58 \pm 1.16^{\mathrm{a}}$ & $6.58 \pm 1.16^{\mathrm{a}}$ & $6.58 \pm 1.16^{\mathrm{a}}$ & $6.58 \pm 1.16^{\mathrm{a}}$ & $6.16 \pm 1.02^{a}$ \\
\hline $\begin{array}{c}\text { Rectal } \\
\text { temperature }\left({ }^{\circ} \mathrm{C}\right)\end{array}$ & $7.20 \pm 0.32^{\mathrm{a}}$ & $6.86 \pm 0.31^{\mathrm{a}}$ & $6.81 \pm 0.35^{\mathrm{a}}$ & $6.86 \pm 0.35^{\mathrm{a}}$ & $6.78 \pm 0.42^{\mathrm{a}}$ & $6.84 \pm 0.38^{\mathrm{a}}$ & $6.90 \pm 0.26^{\mathrm{a}}$ \\
\hline $\begin{array}{l}\text { Respiratory rate } \\
\text { (Breaths per } \\
\text { minutes) }\end{array}$ & $8.66 \pm 1.52^{\mathrm{a}}$ & $8.50 \pm 2.18^{a}$ & $4.16 \pm 0.65^{\mathrm{a}}$ & $5.50 \pm 1.36^{\mathrm{a}}$ & $6.50 \pm 1.74^{\mathrm{a}}$ & $5.50 \pm 0.95^{\mathrm{a}}$ & $6.50 \pm 1.14^{a}$ \\
\hline $\begin{array}{l}\text { Heart rate (beats } \\
\text { per minute) }\end{array}$ & $6.00 \pm 1.26^{\mathrm{a}}$ & $6.66 \pm 1.68^{\mathrm{a}}$ & $8.00 \pm 1.46^{\mathrm{a}}$ & $5.66 \pm 1.40^{\mathrm{a}}$ & $6.33 \pm 1.20^{\mathrm{a}}$ & $5.33 \pm 2.04^{a}$ & $6.33 \pm 2.09^{a}$ \\
\hline
\end{tabular}

Means with same superscripts do not vary significantly $(\mathrm{p}>0.05)$

T1: Before Rumenotomy, T2: Before Diaphragmatic herniorrhaphy, T3: 15minutes after Glycopyrrolate, T4: 10 minutes after Xylazine, T5: 15 minutes after Tolfenamic acid, T6: At recovery, T7: 24 hours after Diaphragmatic herniorrhaphy.

Table.4 Effects of Glycopyrrolate - Xylazine - Flunixin-meglumine - Ketamine combination on rectal temperature, heart rate and respiratory rate in six buffaloes. Mean value presented with respective standard errors $( \pm)$

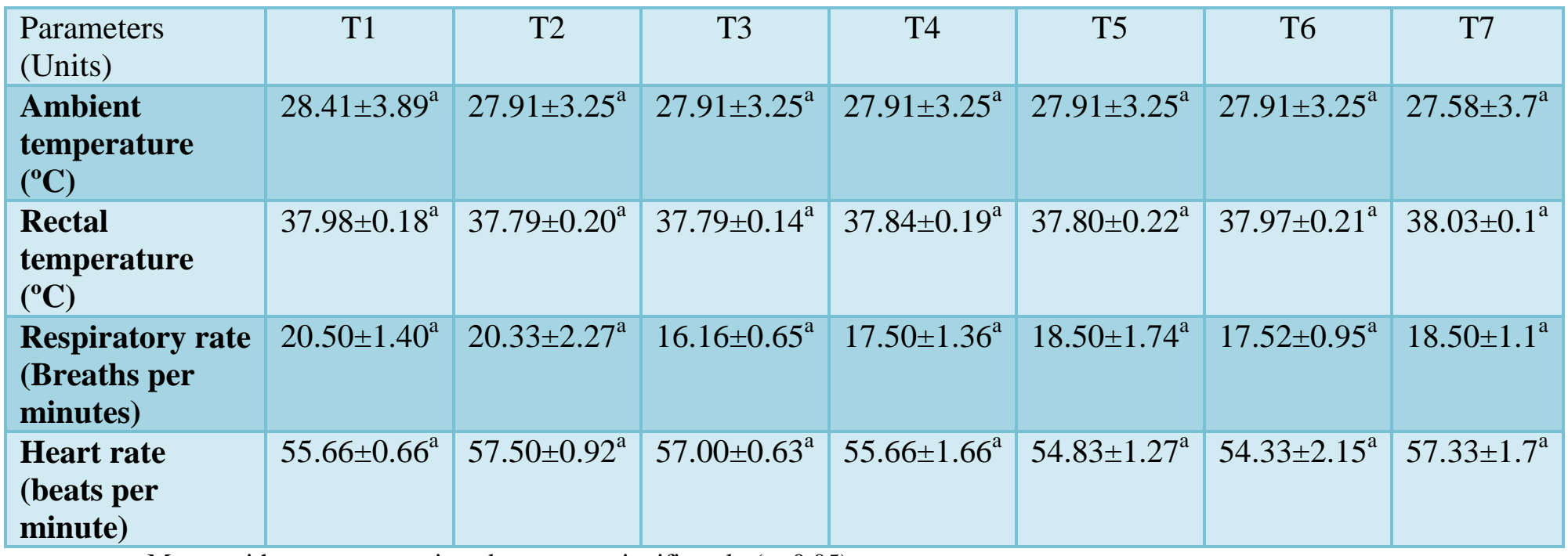

Means with same superscripts do not vary significantly $(\mathrm{p}>0.05)$

T1: Before Rumenotomy, T2: Before Diaphragmatic herniorrhaphy, T3: 15minutes after Glycopyrrolate, T4: 10 minutes after Xylazine, T5: 15 minutes after Flunixin-meglumine, T6: At recovery, T7: 24 hours after Diaphragmatic herniorrhaphy. 
A significant reduction in heart rate, was reported in buffalo calves given Xylazine $\mathrm{i} / \mathrm{m}$ at $0.22 \mathrm{mg} / \mathrm{kg} \mathrm{kg}$ body weight (Peshin and Kumar, 1979); in cattle given an intramuscular dose of Xylazine @ $0.22 \mathrm{mg} / \mathrm{kg}$ and an intravenous dose of Ketamine @ 11.0 $\mathrm{mg} / \mathrm{kg}$ (Kumar and Singh, 1979) which contradicts the findings. Contrary statement on bradycardia after an intramuscular administration of Xylazine at $0.22 \mathrm{mg} / 100 \mathrm{~kg}$ body weight in calves was given by Campbell et al., (1979) and in cattle given Xylazine $\mathrm{i} / \mathrm{m}$ at a dose rate of $0.05 \mathrm{mg} / \mathrm{kg}$ (Hall and Clarke, 1969). Heart rate is a complex physiological variable that can also be altered by fear, stress, degree of anaesthesia and vascular volume (Conzemius et al., 1997 and Lin et al., 1993). Rectal temperature did not show any significant variation during the entire period of observation. Meloxicam is a potent inhibitor of prostaglandins and exhibits analgesic, and antipyretic properties (Engelhardt, 1995). Rectal temperature has been found to be a poor indicator of postoperative pain in small animals (Smith et al., 1996).

\section{Group 2}

\section{Physiological Study}

There was no significant variation in rectal temperature and respiration rate during the entire period of observation. A nonsignificant increase in the heart rate was observed 15 minutes after Glycopyrrolate administration from the base value $56.00 \pm 1.26$ to $58.00 \pm 1.46$ beats per minute, then non-significantly decreased to $55.66 \pm 1.40$ beats per minute 10 minutes after Xylazine administration. Absorption of Glycopyrrolate is rapid after intramuscular administration and the onset of cardiovascular effects occurs within 5 minutes, peak effects within 20 minutes and heart rate remains elevated approximately for 1 hour (Lemke, 2001). It has positive chronotropic effects in horses which is followed by an increase in cardiac output and arterial blood pressure. As high as $50 \%$ increase of heart rate from base value has been reported at 20 minutes of injection. This was followed by $38 \%$ increase in cardiac output and $31 \%$ increase in mean arterial pressure (Neto et al., 2004). A significant reduction in heart rate, respiration rate, and mean arterial pressure was reported in buffalo calves given Xylazine $\mathrm{i} / \mathrm{m}$ at $0.22 \mathrm{mg} / \mathrm{kg}$ body weight (Peshin and Kumar, 1979). A statistically significant reduction in heart rate was seen in cattle given an intramuscular dose of Xylazine @ $0.22 \mathrm{mg} / \mathrm{kg}$ and an intravenous dose of Ketamine @ $11 \mathrm{mg} / \mathrm{kg}$ (Kumar and Singh, 1979).

\section{Group 3}

\section{Physiological Study}

There was no significant variation in rectal temperature during the entire period of observation. The values of respiratory rate and heart rate fluctuated non-significantly at various intervals. No effect on heart rate was observed by Sharma et al., (1983) in cattle given Xylazine $(0.1 \mathrm{mg} / \mathrm{kg})-$ Ketamine anaesthesia either by intramuscular $(5 \mathrm{mg} / \mathrm{kg})$ or intravenous route $(2 \mathrm{mg} / \mathrm{kg})$. A significant reduction in heart rate, was reported in buffalo calves given Xylazine $\mathrm{i} / \mathrm{m}$ at $0.22 \mathrm{mg} / \mathrm{kg} \mathrm{kg}$ body weight (Peshin and Kumar, 1979); in cattle given an intramuscular dose of Xylazine @ $0.22 \mathrm{mg} / \mathrm{kg}$ and an intravenous dose of Ketamine @ 11.0 $\mathrm{mg} / \mathrm{kg}$ (Kumar and Singh 1979) which contradicts the findings.

In conclusion, the present study indicates that no significant variations were observed in rectal temperature, heart and respiratory rates during the entire period of observation in group 1 while in group 2there was no significant variation in rectal temperature and respiration rate during observation period. A 
non-significant increase in the heart rate was observed 15 minutes after Glycopyrrolate administration from the base value $56.00 \pm 1.26$ to $58.00 \pm 1.46$ beats per minute, and then non-significantly decreased to $55.66 \pm 1.40$ beats per minute, 10 minutes after Xylazine administration. In group 3 treated animals there was no significant variation in rectal temperature during the entire period of observation. The values of respiratory rate and heart rate fluctuated non-significantly at various intervals.

\section{References}

Campbell, K.B., Klavano, P.A., Richardson, P. and Alexander, J. E. 1979.Haemodynamic effects of xylazine in the calf. Am. J. Vet. Res. 40(12): 1777-1780.

Conzemius, M. G., Hill, C. M., Sammarco, J. L. and Perkowski, S. Z. 1997. Correlation between subjective and objective measures used to determine severity of postoperative pain in dogs. J. Am. Vet. Med. Assoc., 210: 1619-1622.

Dar, S. H., Bhadwal, M. S. and Zama, M. M. S. 2013.Post-operative analgesia in dogs by Tramadol and Nimesulide. Indian Vet. J., 90(2): 32-34.

Deneuche, A. J., Dufayet, C., Goby L., Fayolle, P. and Desbois, C. 2004.Analgesic comparison of meloxicam and ketoprofen for orthopedic surgery in dogs. Vet. Surg. 33: 650-660.

Engelhardt, G., Homma, D., Schlegel, K., Utzmann, R. and Schnitzler C. 1995.Antiinflammatory, analgesic, antipyretic and related properties of meloxicam, a new non-steroidal anti-inflammatory agent with favourable gastrointestinal tolerance. Inflamm. Res., 44: 423-433.

Hall, L. W. and Clarke, K. W. 1969."Xylazine"a new sedative for horses and cattle. Vet. Rec.85: 512-517.

Hall, L. W. and Clarke, K. W. 1991.Principles of sedation, analgesia and premedication. In: Veterinary Anaesthesia. $9^{\text {th }}$ edn.Baillire Tindal, London.pp.75-112.
Hall, L. W., Clarke, K. W. and Trim, C. M. 2001.Principle of sedation, analgesia and premedication. In: Veterinary Anaesthesia. $10^{\text {th }}$ edn. W. B. Saunders, London.

Hall, L. W., Clarke, K. W. and Trim, C. M. 2001a.Principles of sedation, analgesia and premedication. In: Veterinary Anaesthesia. $10^{\text {th }}$ edn. W. B. Saunders. London. pp.75-112.

Khan, I., Kumar, A; Singh, J; Peshin, P.K. and Singh, S. 2007 a. Evaluation of glycopyrrotate as an anticholinergic in buffalo calves (Bubalus bubalis). Italian J. Anim. Sci. 6(2): 1007-1010.

Khan, I., Kumar, A., Singh, J., Peshin, P.K. and Singh, S. 2007 b. Evaluation of glycopyrrolate-xylazine as a sedative in buffalo calves (Bubalusbubalis). Italian J. Anim. Sci.6(2): 1011-1014.

Krishnamurthy, D., Nigam, J. M., Peshin, P. K., Sharma, D. N., and Tyagi, R. P. S. 1985. Monograph on diaphragmatic hernia in bovines. Directorate of Publications, Haryana Agricultural University, Hisar, India.

Kumar, A and Singh, H. P. 1979. Ketamine and xylazine anaesthesia in bovine paediatric surgery. Indian Vet. J.56(3): 219-222.

Lascelles, B. D. X., Henderson, A. J. and Hackett, I. J. 2001. Evaluation of the clinical efficacy of meloxicam in cats with painful locomotor disorders. J. Small Anim. pract. 42: 587-593.

Lecoindre, P.,Thomas, E. and Richard, P. (1995). Evaluation of new therapeutic regimen of tolfenamic acid in the treatment chronic painful locomotor syndromes in dog. Proceedings of $2^{\text {nd }}$ European Congress of the Federation of European companin Animal Veterinary Associationsp. 123, Brussels 27-29 Oct 1995.

Lemke, K. A. 2001. Electrocardiographic and cardiopulmonary effects of intramuscular administration of glycopyrrolate and romifidinein conscious beagle dogs. Vet Anaesth Analg. 28: 75-86.

Lin, H. C., Benson, G. J., Thrumon, J. C., 
Tranquilli, W. J., Olson, W. A. and Bevill, R. F.1993. Influence of Anaesthetic Regimens on the Perioperative Catecholamines Response Associated with Onychetomy in Cats. Am. J. Vet. Res.54: 1721-1724.

Mathews, K. A. 2001 Perioperative use of nonsteroidal anti-inflammatory analgesics. Proceedings World Small Animal Vet. Assoc. Congress. (WSAVA-2001).

Neto,F. J. T., McDonell, W. N. ; Black, W. D. and Durongphonton, S. 2004. Effects of glycopyrrolate on cardiorespiratory function in horses. anaesthetized with halothane and xylazine. Am. J. Vet. Res. 65: 456-463.

Pageat, P. 1986. Clinical study of recurrent hallucination after ketamine anaesthesia in dogs and cats: 39 cases. Pratiqu eMedicale and Chirugicale de l' Animal de Compagnie. 21:185-190.

Pathak, S. C., Nigam, J. M., Peshin, P. K. and Singh, A. P. 1982. Anaesthetic and hemodynamic effects of ketamine hydrochloride in buffalo calves. (Bubalus bubalis). Am. J. Vet. Res.43: 875-878

Peshin, P. K. and Kumar, A. 1979. Physiologic and sedative effects of xylazine in buffaloes. Indian Vet. J. 56: 864-871.

Sahu, A.,Chawla, S.K., Krishnamurthy, D. 2003. Diaphragmatic herniorrhaphy in buffaloes: clinical evaluation of 72cases," Indian Journal of Veterinary Surgery, vol. 24, pp. 33-34.

Saini, N.S., Kumar, A.,.Mahajan, S.K. and. Sood, A.C. 2007. The useof ultrasonography, radiography, and surgery in the successful recovery from diaphragmatic hernia in a cow," Canadian Veterinary Journal, vol. 48, no. 7, pp. 757-759.

Semrad, S. D., Hardee, G. E., Hardee, M. M. 1985. Flunixin-meglumine given in small doses: pharmacokinetics and prostaglandin inhibition in healthy horses. Am. J. Vet. Res., 46: 2474-2479.

Sharma, A. K., Kumar, A. and Singh, H. 1983. Clinical use of procaine, xylazine, chlorpromazine and triflupromazine hydrochloride in thiopentone anaesthesia in canine surgery. Indian Vet. J.60(17): 921-924.

Singh, S., Kumar, A., Singh, J., Singh, S. and Peshin, P. K. 2006. Haemodynamic effects of atropine-diazepam-thiopentone anaesthesia in buffalo calves. Indian $J$. Vet. Res. 15(1): 22-30.

Smith, J. D., Allen, S. W., Quandt, J. E. 1996.Indicators of postoperative pain in cats and correlation with clinical criteria. Am J Vet Res57:1674-1678.

Sobti, V.K., Sharma, S.N., Singh, K. and Rathor, S.S. 1989.Diaphragmatic hernia in buffalo bulls," Indian Veterinary Journal, vol. 66, p. 866,

\section{How to cite this article:}

Lokesh, Praveen Kumar, Anup Yadav, Ashwani kumar, Rishi Tayal, PankajKumar, RajendraYadav and Diwakar, R.P. 2018. Physiological Studies in Buffaloes Affected with Diaphragmatic Hernia with Different Treatment Protocols. Int.J.Curr.Microbiol.App.Sci. 7(12): 1058-1066. doi: https://doi.org/10.20546/ijcmas.2018.712.132 